\title{
Correspondence
}

\section{Association of 13q deletion and Hirschsprung's disease}

SIR,

It was interesting to read the paper by Lamont et $a l^{1}$ about the association of $13 \mathrm{q}$ deletion and Hirschsprung's disease. We have observed a similar case.

An eight month old boy was investigated in our genetic service. The family history was negative. The mother's first pregnancy ended with a spontaneous abortion. The proband was born of the second uneventful pregnancy with a birthweight of

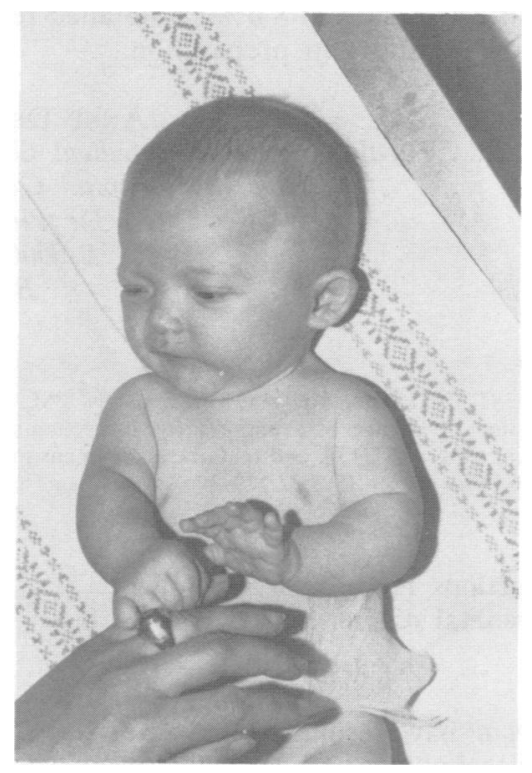

FIG 1 Eight month old male infant with craniofacial dysmorphism. Sigmoidostomy still open.

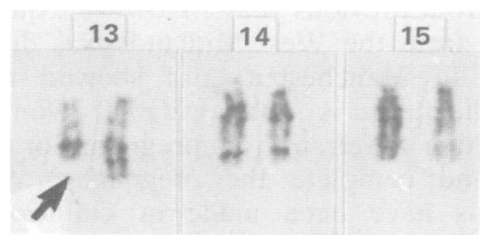

FIG $2 \operatorname{Del}(13)(q 22 \rightarrow q t e r)(G A G$ banding).

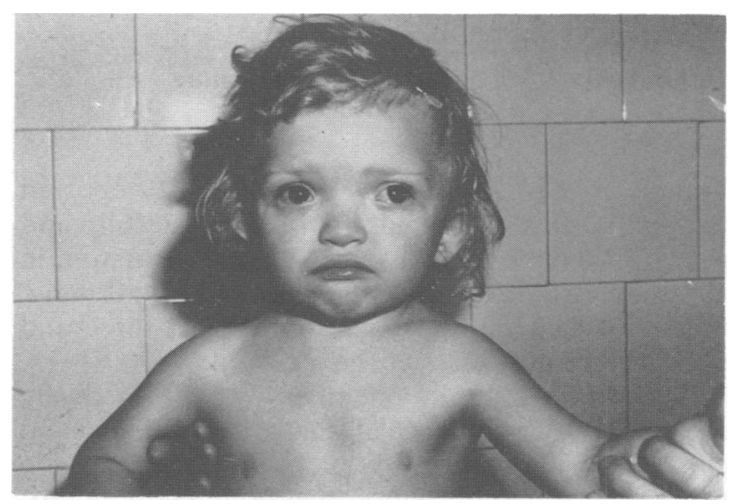

FIG 3 The patient at three years showing craniofacial dysmorphism, hypertelorism, low set ears, and small chin.

$3000 \mathrm{~g}$. At two weeks of age Hirschsprung's disease was diagnosed and sigmoidostomy was performed.

At eight months of age the following features were observed: mild craniofacial dysmorphism (fig 1) including hypertelorism, strabismus, small nose, and low set ears, a simian crease on the left palm, a small penis, and bilateral cryptorchidism. Cytogenetic analysis was carried out using GAG, G, and $C$ banding techniques. The karyotype was $46, X Y, \operatorname{del}(13)$ (q22 $\rightarrow$ qter) (fig 2). The karyotypes of the parents were normal. At three years of age the craniofacial dysmorphism was more pronounced (fig 3 ) and there was marked psychomotor retardation.

It is well known that Hirschsprung's disease may be associated with various dysmorphic syndromes and occasionally with structural autosomal aberrations, ${ }^{2}$ but it usually occurs as a single malformation. Further observations are needed to ascertain any association between $13 q$ deletion and Hirschsprung's disease. However, if the $\mathrm{q} 22$ region is involved in the deletion, as in the two cases observed by Lamont et $a l^{1}$ and in our case, this connection should be given serious consideration.

Péter Kiss AND

Magda Osztovics Apáthy Paediatric Hospital, Pf 112, H-1442 Budapest; and National Institute of Public Health, Budapest, Hungary. 


\section{References}

1 Lamont MA, Fitchett M, Dennis NR. Interstitial deletion of $13 q$ associated with Hirschsprung's disease. J Med Genet 1989;26: $100-4$.

${ }^{2}$ Bankier A. Hirschsprung's disease, distinctive facies, and microcephaly. J Med Genet 1989;26:287-8.

\section{Dominantly inherited cleft lip and palate}

SIR,

Temple et al (J Med Genet 1989;26:386-9) reported two families with dominantly inherited cleft lip and palate. We have recently seen a similar situation in a family (figure) presenting with non-syndromic, unilateral cleft lip and palate in at least three and probably four successive generations.

All affected family members were personally examined and in none of them could associated clinical findings suggestive of Van Der Woude syndrome or another autosomal dominantly inherited syndrome associated with cleft lip and palate be found.

III. 5 and his wife asked for genetic advice after his healthy sister (III.10) gave birth to her first child (IV.5) with a left sided cleft of the lip, hard and soft palates, and alveolus. No lip pits or fistulae were present and the child was otherwise normal. On thorough clinical and $x$ ray examination, no minimal signs of cleft lip/palate were found in III.10. The child's father (III.9) had no clinical abnormalities and his family history was negative.

One brother (III.2), one sister (III.4), and a niece (IV.3) of the consultand were born with a right sided cleft of the lip and palate. His mother (II.2) also had a cleft lip and palate at birth. She underwent several surgical repairs, including closure of the lip in early childhood, closure of the palate at 50 years of age, and a Lefort I type osteotomy because of retrognathia of the maxilla and hypoplasia of the upper

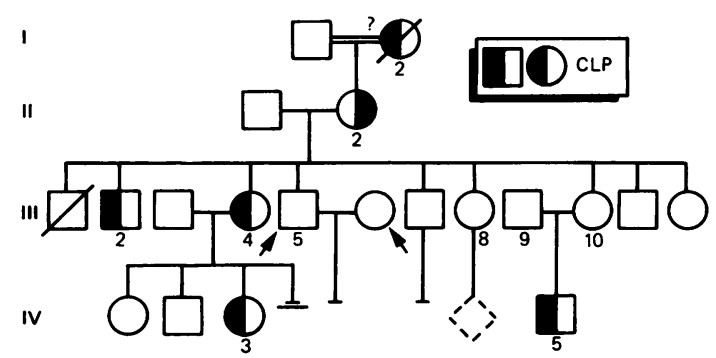

FIGURE Pedigree of family with unilateral cleft lip and palate in four generations. ? represents a reportedly affected family member. 1.1 and 1.2 are consanguineous. cheek. No preoperative photographic data were available but clinical examination showed that the cleft had been right sided. According to all family members, the dead maternal grandmother (I.2) had also had a unilateral cleft lip and palate.

Except for II.2, whose parents were first cousins, consanguinity was excluded between the parents of all the other affected family members.

The linear pattern of inheritance in this family is suggestive of autosomal dominant rather than multifactorial inheritance and adds further evidence to the hypothesis, which has already been suggested in other family studies, ${ }^{1}$ that a single major dominant gene is responsible for cleft lip and palate in some families.

If we accept an autosomal dominant transmission pattern in this family, subject III.10 is a nonpenetrant heterozygote. Under the assumption of autosomal dominant inheritance with reduced penetrance, III.5 and his wife were given a maximum risk for an affected child of $8 \cdot 6 \%$. A detailed report of this family study is in preparation. Faculty Centre for Medical Genetics, University Hospital Gent K5 185 De Pintelaan B-9000 Gent $=$ Belgium?

\section{Reference \\ 1 Eiberg H, Bixler D, Nielson S, Conneally PM, Mohr J. Suggestion of linkage of a major locus for a non-syndromic orofacial cleft with F13A and tentative assignment to chromo- some 6. Clin Genet 1987;32:129-32.}

\section{Are abortions more or less frequent} once prenatal diagnosis is available?

SIR,

Harris et $^{1} \mathrm{l}^{1}$ have recently stated that the application of DNA techniques to inherited diseases reduces the risks of fetuses being aborted, since the majority will be found to be healthy after testing; they report 18 abortions of fetuses at risk for Duchenne muscular dystrophy, and state that this number is a reduction from previous years. However, our early experience from the West Midlands was different from that in Manchester, and showed that if prenatal diagnosis is not available, women at risk tend either to refrain from pregnancy or to take the risk and complete the pregnancy. ${ }^{2}$ Similar observations have been made in Ontario. ${ }^{3} \mathrm{We}$ thought it important to be certain of women's attitudes and behaviour before analysing any effect 